Article

\title{
Finding the Way to Improve Motor Recovery of Patients with Spinal Cord Lesions: A Case-Control Pilot Study on a Novel Neuromodulation Approach
}

\author{
Antonino Naro ${ }^{1}$, Luana Billeri ${ }^{1}{ }^{\mathbb{D}}$, Tina Balletta ${ }^{1}$, Paola Lauria ${ }^{1}$, Maria Pia Onesta ${ }^{2}$ \\ and Rocco Salvatore Calabrò ${ }^{1, *(D)}$
}

check for

updates

Citation: Naro, A.; Billeri, L.; Balletta,

T.; Lauria, P.; Onesta, M.P.; Calabrò,

R.S. Finding the Way to Improve

Motor Recovery of Patients with

Spinal Cord Lesions: A Case-Control

Pilot Study on a Novel

Neuromodulation Approach. Brain Sci. 2022, 12, 119. https://doi.org/ 10.3390/brainsci12010119

Academic Editor: Manuel Gaviria

Received: 15 December 2021

Accepted: 13 January 2022

Published: 17 January 2022

Publisher's Note: MDPI stays neutral with regard to jurisdictional claims in published maps and institutional affiliations.

Copyright: (C) 2022 by the authors. Licensee MDPI, Basel, Switzerland. This article is an open access article distributed under the terms and conditions of the Creative Commons Attribution (CC BY) license (https:// creativecommons.org/licenses/by/ $4.0 /)$.
1 IRCCS Centro Neurolesi Bonino Pulejo Piemonte, Via Palermo, SS 113, Ctr. Casazza, 98124 Messina, Italy; g.naro11@alice.it (A.N.); luanabilleri@hotmail.it (L.B.); tina.balletta@irccsme.it (T.B.); paola.lauria@irccsme.it (P.L.)

2 Spinal Cord Unit, Cannizzaro Hospital, 95126 Catania, Italy; mp.onesta@virgilio.it

* Correspondence: salbro77@tiscali.it; Tel.: +39-09060128340

\begin{abstract}
Robot-assisted rehabilitation (RAR) and non-invasive brain stimulation (NIBS) are interventions that, both individually and combined, can significantly enhance motor performance after spinal cord injury (SCI). We sought to determine whether repetitive transcranial magnetic stimulation (rTMS) combined with active transvertebral direct current stimulation (tvDCS) (namely, NIBS) in association with RAR (RAR + NIBS) improves lower extremity motor function more than RAR alone in subjects with motor incomplete SCI (iSCI). Fifteen adults with iSCI received one daily session of RAR+NIBS in the early afternoon, six sessions weekly, for eight consecutive weeks. Outcome measures included the 6 min walk test (6MWT), the $10 \mathrm{~m}$ walk test (10MWT), the timed up and go (TUG) to test mobility and balance, the Walking Index for Spinal Cord Injury (WISCI II), the Functional Independence Measure-Locomotion (FIM-L), the manual muscle testing for lower extremity motor score (LEMS), the modified Ashworth scale for lower limbs (MAS), and the visual analog scale (VAS) for pain. The data of these subjects were compared with those of 20 individuals matched for clinical and demographic features who previously received the same amount or RAR without NIBS (RAR - NIBS). All patients completed the trial, and none reported any side effects either during or following the training. The 10MWT improved in both groups, but the increase was significantly greater following RAR + NIBS than RAR - NIBS. The same occurred for the FIM-L, LEMS, and WISCI II. No significant differences were appreciable concerning the 6MWT and TUG. Conversely, RAR - NIBS outperformed RAR + NIBS regarding the MAS and VAS. Pairing tvDCS with rTMS during RAR can improve lower extremity motor function more than RAR alone can do. Future research with a larger sample size is recommended to determine longer-term effects on motor function and activities of daily living.
\end{abstract}

Keywords: gait motor function; neuroplasticity; direct current stimulation; spinal cord injury; robotaided gait training

\section{Introduction}

Spinal cord injury (SCI) affects between 250,000 and 500,000 persons annually worldwide [1], often causing severe and permanent loss of motor, sensory, or autonomic functions. In addition, SCI has a striking socio-economic impact, as it often affects young people of working age. SCI thus requires an intensive rehabilitative approach to counteract the residual functional impairment [2].

Motor recovery occurs mainly within the first two months after SCI. However, chronic SCI patients may also have chances to recover further motor function with adequate, intensive training [3]. In this regard, robotic rehabilitation devices have been increasingly 
utilized as an adjunct therapy to the conventional rehabilitation strategies for individuals with SCI [4]. The rationale of adopting robot-aided rehabilitation (RAR) consists of enhancing motor function recovery through highly repeated functional movements and the entrainment of residual neural plasticity mechanisms subtending functional recovery, at either the spinal central pattern generator [5] or cortical level [6,7]. Furthermore, RAR allows counteracting the numerous constraints in providing an individualized training strategy, including reduced sensorimotor coordination, spasticity, and impaired balance [8]. Finally, RAR serves as a mobility aid beyond orthoses and wheelchairs [4].

Many promising RAR interventions have been shown to improve the mobility, function, and quality of life of individuals with SCI, in particular regarding lower extremity robotic exoskeletons. However, the majority of the available works have methodological and rehabilitation paradigm differences, thus being unable to demonstrate the superiority of one gait training strategy over another in counteracting the loss of muscle strength and trophism, walking disability and mobility, sensory dysfunction, autonomic disorders, spasticity, pain, and overall quality of life [9-15]. Therefore, more extensive studies are required to prove RAR's benefits definitively [4].

Similar to RAR research in SCI patients, more innovative ways to stimulate the brain and spinal plasticity to promote functional recovery have been investigated. Mainly, noninvasive brain stimulation (NIBS) has been adopted to potentiate the therapeutic benefits of RAR [16]. The rationale of coupling NIBS with RAR mainly stems from the possibility to couple bottom-up (RAR) and top-down (NIBS) plasticity processes, thus better targeting the neural pathways that are responsible for motor (re)learning processes and are entrained during the rehabilitation processes owing to intensive, repetitive, assisted-as-needed, and task-oriented approaches [6,16-18]. However, significant concerns remain about NIBS's administration time, order effect, and blinding when coupled to RAR. Therefore, further investigations are required to better assess the effects of this paired approach on motor function recovery following SCI, as demonstrated in patients with stroke $[19,20]$.

The study aimed at ascertaining whether NIBS paired with RAR could provide SCI patients with superior outcomes related to gait, spasticity, and pain than stand-alone RAR. Given that we focused on the potential efficacy of a combined training with RAR and NIBS on gait, we considered only ambulatory individuals (i.e., incomplete SCI-iSCIwith ASIA C-D). Moreover, we recruited only chronic iSCI patients (i.e., more than 6 mo post-injury) so as to have individuals with a stable level of recovery, which could suggest that the observed improvements may depend on the intervention itself rather than on a spontaneous recovery [21], and without medical conditions that could preclude RAR utilization.

\section{Materials and Methods}

\subsection{Participants and Study Design}

We consecutively enrolled patients with SCI attending our Neurorobotic Unit between January 2016 and December 2019. Inclusion criteria were: (i) chronic (onset more than $6 \mathrm{mo}$ ), non-progressive (traumatic or non-traumatic), thoracic (between T3 and T10) iSCI (classified by the ASIA Impairment Scale (AIS) as grades C and D at entry); (ii) age range 18-65 y. In addition, pressure ulcers, severe range of motion limitation due to spasticity or tendon retraction, severe bone, heart, or pulmonary disease, and NIBS contraindication (e.g., implanted electromechanical devices) represented the exclusion criteria.

We screened 35 patients, 15 of whom were included in the study. The patients were evaluated at baseline (T0) using clinical scales as outcome measures. Then, patients were provided with a NIBS session followed by a RAR session. Each subject was provided with a daily session of RAR + NIBS in the early afternoon (six sessions weekly), for eight consecutive weeks. The patients were then evaluated immediately after (T1) and three months after (T2) the training, using the above clinical scales. The data of these subjects were compared with those coming from a sample of 20 individuals matched for clinical and demographic features who previously underwent the same amount or RAR without NIBS 
(RAR - NIBS). The clinico-demographic characteristics of both groups are summarized in Table 1.

Table 1. Clinico-demographic characteristics (summarized as percentage or mean $\pm \mathrm{sd}$ ).

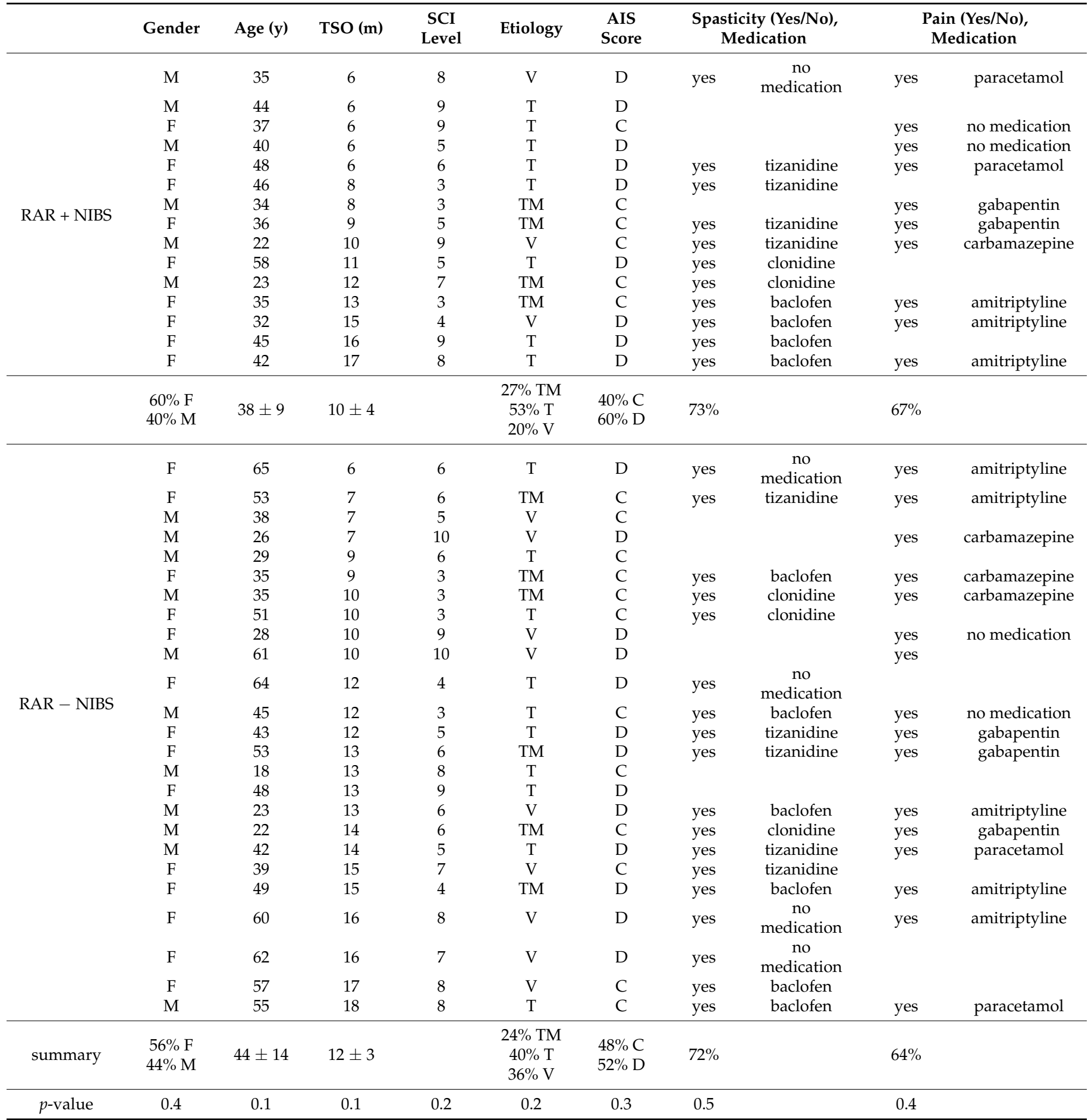

Legend: RAR, robot-aided rehabilitation; NIBS, non-invasive brain stimulation; AIS, ASIA Impairment Scale; C and D, AIS grades at study entry; F, female; M, male; $\mathrm{m}$, months; SCI, spinal cord injury; T, trauma; TM, transverse myelitis; V, vascular; y years; TSO, time from SCI onset. p-value of between-group comparison.

\subsection{Outcome Measures}

We used the 6 min walk test (6MWT) and the $10 \mathrm{~m}$ walk test (10MWT) to measure ambulatory ability and endurance [22-24]. The timed up and go (TUG) allows testing 
mobility and balance $[25,26]$. The Walking Index for Spinal Cord Injury (WISCI II; scoring from 1 to 20) addresses the amount of physical assistance, braces, or devices required to walk $10 \mathrm{~m}$ [27]. The Functional Independence Measure-Locomotion (FIM-L) quantifies the need for assistance when performing physical, psychological, and social functions [28,29]. The manual muscle testing for lower extremity motor score (LEMS; five key muscles-hip flexors, knee extensors, ankle dorsiflexor, long toe extensors, and ankle plantar flexors-of both lower extremities; range 0 to 50) was conducted according to the ASIA standard. Spasticity was assessed using the modified Ashworth scale (MAS) for lower limbs. The visual analog scale (VAS) was used to quantify individual estimation of pain [30].

\subsection{Non-Invasive Brain Stimulation}

NIBS consisted of a repeated transcranial magnetic stimulation (rTMS) paradigm carried out simultaneously with a cathodal transvertebral direct current stimulation (tvDCS) (also known as transcutaneous spinal direct current stimulation) paradigm.

rTMS was delivered using a Magstim Super-Rapid2 stimulator (Magstim Company, Whitland, U.K.) equipped with a double-cone coil (each wing measuring $110 \mathrm{~mm}$ in diameter) perpendicularly held over the vertex, in order to trigger both legs' primary motor areas. According to a brain MRI scan, the stimulation site was identified and marked on a personal head-cap. Coil positioning was carefully documented (including position, angulation, and inclination) to keep it constant along with rTMS sessions. The coil was held in position by a mechanical support. The stimulation intensity was set at $90 \%$ of the right tibialis anterior muscle resting motor threshold (RMT). Each session consisted of 60 bursts of 20 pulses at $10 \mathrm{~Hz}$ with inter-train intervals of $10 \mathrm{~s}$, for 1200 pulses.

tvDCS was delivered using a Brain Stim device (EMS; Bologna, Italy) equipped with two rubber electrodes of $49 \mathrm{~cm}^{2}$ inserted in a saline-soaked sponge, which were fixed over two metameres above the site of spinal lesion, serving as the active electrode, and over the left deltoid, serving as the reference electrode. Skin impedance was adequately reduced using abrasive gel and then wiped clean with alcohol swabs. The stimulation intensity was set at $2 \mathrm{~mA}$ and lasted $20 \mathrm{~min}$ (current density of $0.041 \mathrm{~mA} / \mathrm{cm}^{2}$ and charge density of $0.048 \mathrm{C} / \mathrm{cm}^{2}$ ). The current was ramped up to the full intensity over $30 \mathrm{~s}$ at the onset of tvDCS and ramped down over $30 \mathrm{~s}$ at the end.

\subsection{Robot-Aided Rehabilitation}

RAR consisted of a neurorobotic treatment using the LokomatPro (i.e., a Lokomat with an Augmented Performance Feedback) (Hocoma; Volketswil, Switzerland). Lokomat is a robotic device consisting of powered gait orthoses with integrated computer-controlled linear actuators at each hip and knee joint, a body-weight support system (BWSS), and a treadmill [31]. The augmented performance feedback guarantees motivating, challenging, and instructive functional feedback in virtual environments. Patients performed a fortyminute session per day, in the early afternoon, from Monday to Friday, for eight consecutive weeks, for a total of forty sessions. The amount of BWS was initially set at $70 \%$ of the patient's weight, then decreased according to the patient's load tolerance, and the gait speed was adjusted to make the exercise comfortable for the patient. A Lokomat-trained physiotherapist supervised each session. In addition to RAR sessions, patients underwent conventional physical therapy (CPT) twice a day and five-times a week using the Bobath principles, occupational therapy, and functional electrical stimulation.

\subsection{Statistical Analysis}

The primary analysis sought the changes of the 6MWT, 10MWT, TUG, and WISCI II (all gait-related outcome measures) in the two groups from the baseline over the treatment period (T1 vs. T0 and T2 vs. T0). In this regard, ANCOVA was used, adjusting for the baseline value. This analysis was also performed for all the other outcome measures.

The secondary analysis sought the changes from the baseline over the treatment period (T1 vs. T0 and T2 vs. T0) of the outcome measures depending on the baseline ASIA scorings 
using a two-way ANOVA with group (2 levels: RAR + NIBS and RAR - NIBS) and time (3 levels: T0, T1, and T2) as factors. Pairwise comparisons with Bonferroni correction were tested.

Finally, we categorized the subjects as improved (WISCI II changes superior to the MCID) or not improved (WISCI II changes non-superior to the MCID) to identify possible predictors of recovery after rehabilitation. To this end, we used a multivariable logistic regression with the clinico-demographic features at the baseline (age, gender, time since SCI, NLI, etiology, AIS score, presence of spasticity, presence of pain, and LEMS value) as candidate predictors.

All the analyses were conducted according to an intention-to-treat analysis, thus including all participants for which data were available. The significance level of the statistical data was set at $\alpha<0.05$.

We estimated that 64 individuals should be studied assuming $80 \%$ power, a type I error of 0.05 , a mean difference of $30 \%$ on the WISCI II, and a dropout rate of $10 \%$.

The experimenters who analyzed the data were blinded to the patients' allocation.

\section{Results}

There were no significant differences in the clinico-demographic features and treatment periods between the groups. Most participants were taking medications (as shown in Table 1). However, all participants were hospitalized at the Neurorobotic Unit of our Institute so that the patients' medication status was easily controlled. Further, patients were not provided with any medication change during the experimental period.

All patients completed the trial, and none reported any side effects during or after the training. The 10MWT improved in both groups, but the increase was more significant following RAR + NIBS than RAR - NIBS (Table 2). The same occurred for the FIM-L, LEMS, and WISCI II. No significant differences were appreciable concerning the 6MWT and TUG. Conversely, RAR - NIBS outperformed RAR + NIBS concerning the MAS and VAS.

Table 2. Outcome measures and statistical data.

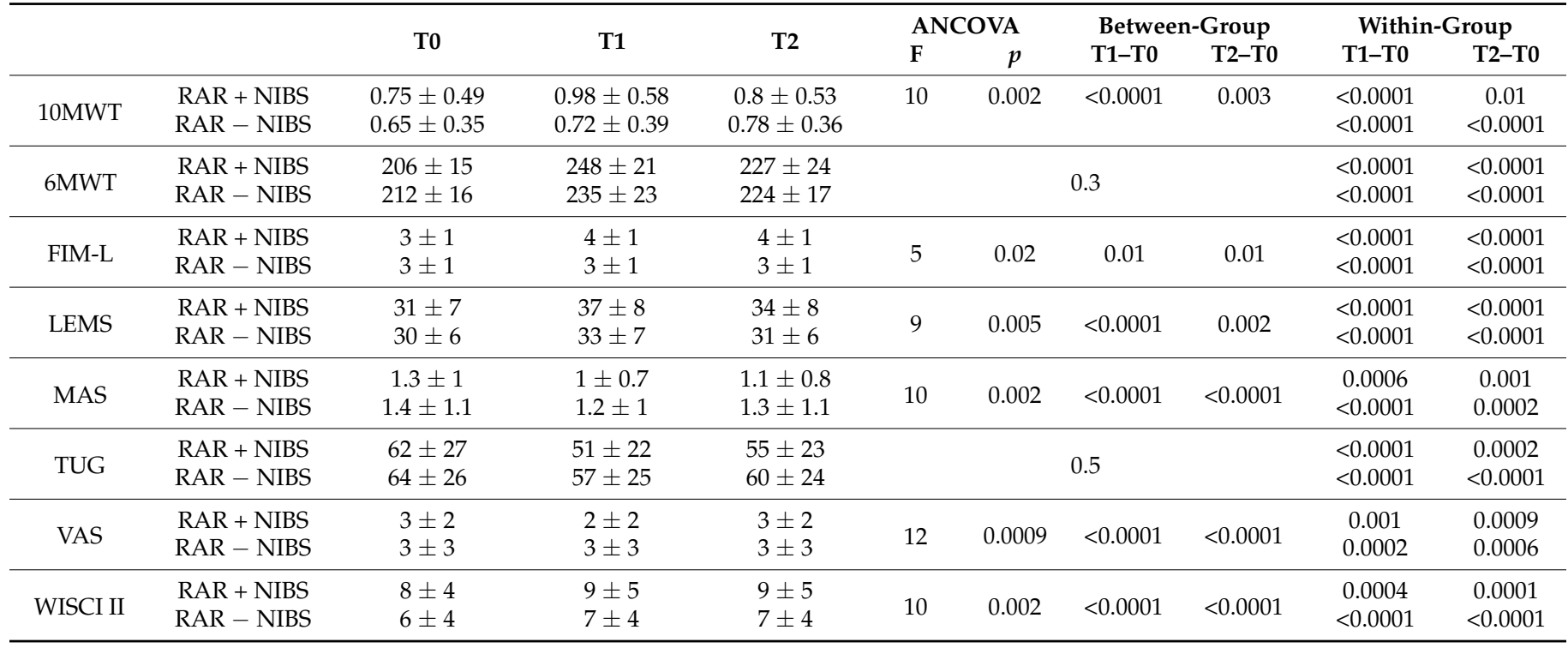

Legend: robot-aided rehabilitation (RAR), non-invasive brain stimulation (NIBS), 6 min walk test (6MWT), 10 $\mathrm{m}$ walk test (10MWT), timed up and go (TUG), Walking Index for Spinal Cord Injury (WISCI II), Functional Independence Measure-Locomotion (FIM-L), lower extremity motor score (LEMS), modified Ashworth scale (MAS), visual analog scale for pain (VAS), Analysis of Covariance (ANCOVA), F-value (F), $p$-value (p).

There was no significant effect of patients' stratification depending on ASIA on clinical outcome measure changes (all $p>0.1$ ).

The significant predictors of recovery were the LEMS, age, and time since injury (all $p<0.0001)$. 


\section{Discussion}

RAR has been proven effective in post-SCI gait rehabilitation, as it can bypass the constraints in providing an individualized training strategy and the main limitations of iSCI individuals in overground walking ability, i.e., sensorimotor coordination, spasticity, impaired balance, and muscle weakness [8,32-36]. Consistently, the RAR - NIBS group showed a significant improvement in ambulation (including walking speed and independence and lower limb muscle strength) with a reduced requirement of assistance after the treatment. In addition, significant spasticity and pain reduction were also appreciable.

These effects could depend on the fact that RAR provides repetitive, intensive, assistedas-needed, and task-oriented treatment, which can entrain the sensorimotor cortex and the cerebellar regions involved in gait control, thus leading to a motor performance improvement [37]. Furthermore, RAR provides proprioceptive inputs to the lower extremities that, consistent with gate control theory, block noxious small fiber afferents, which cause pain and spasticity, thus contributing to gait improvement $[38,39]$.

Therefore, RAR combined with CPT offers some valuable clinical benefits. Contrarily, other studies showed no significant difference between RAR and CPT [9-12,40]. Therefore, further investigation is necessary to find additional strategies to RAR that may further promote rehabilitation outcome achievement.

NIBS has been shown to contain motor impairment and promote spinal fiber functional restoration $[41,42]$. However, to the best of our knowledge, only a few studies have investigated the feasibility and potential efficacy of RAR paired with NIBS on gait performance in individuals with iSCI [43-46]. Remarkably, no study assessed both rTMS and tvDCS contemporarily with RAR.

We found that RAR + NIBS was safe and feasible, as all patients completed the trial and none reported any side effects during or after the training. In addition, all patients were well compliant with the NIBS protocol. The RAR + NIBS group outperformed the RAR - NIBS group concerning gait speed, muscle strength, ambulation autonomy, and disability burden. Conversely, both groups significantly improved in gait endurance, balance, spasticity, and pain, without any between-group difference.

The combined approach could be thus preliminarily considered a training strategy to provide safe and more effective neuromuscular re-education for iSCI patients compared to RAR alone. Another advantage coming from the implementation of NIBS in the RAR strategy lies in its extensive applicability to SCI patients, as its aftereffects were independent of patients' ASIA. However, this requires confirmation by randomized trials, as we adopted a propensity matching analysis for observational studies. Furthermore, some clinical features may critically influence outcome achievement, including baseline LEMS (the better the LEMS, the higher outcomes scores), patients' age (the younger the patient, the higher the outcomes scores), and time since injury (the earlier the rehabilitation period begins, the higher the outcomes scores are). When selecting patients to be submitted to NIBS paradigms, these issues should be taken into account, but clarification and confirmation are needed from randomized clinical trials.

The neurophysiological underpinnings of RAR + NIBS are not clear. The paradigm we implemented, i.e., rTMS paired with tvDCS, is entirely new. Neurophysiological measures were not pursued in this study. Therefore, we can only hypothesize that this double-NIBS may have triggered both spinal and supraspinal mechanisms mediating N-methyl-Daspartate (NMDA) receptor and gamma-aminobutyric acid (GABAergic) activity-mediated neuroplastic changes [47-60]. These mechanisms are also triggered by RAR [5]. Based on these issues and our data, the hypothesis that cathodal tvDCS paired with RAR could induce more evident changes in neuroplasticity and gait compared to RAR alone is plausible. Specifically, the efficacy of the coupled intervention may lie in a shared target by NIBS and RAR, i.e., the activity of spinal interneurons within the central pattern generator. In addition, both approaches may provide sufficient sensory-motor stimulation to optimize neural plasticity [5]. Therefore, a synergistic effect is hypothesized, despite the underlying neurophysiological mechanism remaining partially unclear [61]. These may consist of 
cell death limitation, regeneration and replacement, remyelination, and spinal plasticity mechanisms' modulation [62]. Consistent with our previous findings in stroke models, we suggest that NIBS and RAR potentiate each other in a sort of paired associative stimulation, thanks to either direct cortico-spinal or trans-synaptic spinal effects [61-65].

\section{Limitations}

Our study did not use randomization, which is the major study limitation. Randomized trials enable the unbiased estimation of treatment effects and imply that treatment groups are balanced on average for each covariate. Conversely, the propensity matching analysis of the subjects we adopted may have a limited strength of the beneficial effect of the experimental approach. In addition, there is a non-negligible possibility of bias due to a difference in the treatment outcomes (such as the average treatment effect) because a factor predicts treatment rather than the treatment itself. Unfortunately, for observational studies such as ours, treatment assignment to research subjects is typically not random. However, between-group patient matching (as we did in our study) attempts to reduce the treatment assignment bias and mimic randomization by making a sample of units that receive the treatment comparable to a sample of units that do not receive the treatment concerning all observed covariates. Furthermore, given the novelty of the current approach (combined neuromodulation strategies with RAR), we preferred to implement a pilot trial to examine the safety and feasibility of such a combined neuromodulation approach for iSCI patients, giving insights for further randomized trials. Finally, the propensity matching analysis we adopted also has some advantages, including the estimation of the covariates that predict receiving the treatment and the reduction of the biases due to confounding variables that could be found in an estimate of the treatment effect obtained from simply comparing outcomes among units that receive the treatment versus those that do not [66].

Other limitations of our study include the non-homogenous etiology (traumatic/nontraumatic), the short-term follow-up (up to three months), the lack of neurophysiological measures, the lack of control groups such as sham tvDCS, and tvDCS paired with CPT (only RAR without any NIBS was available). Furthermore, we included in our study only patients in the chronic phase. On the one hand, this limits the applicability of our approach; on the other hand, this sample selection was intended to avoid the bias related to spontaneous recovery, which is commonly observed in acute/subacute patients.

This notwithstanding, our study was intended to preliminarily focus on the safety, feasibility, and potential effectiveness of RAR + NIBS as compared to RAR alone and to provide basic information on determining the appropriateness of candidates and the optimal timing, to design the maximal efficacy of RAR in SCI patients for future randomized clinical trials.

\section{Conclusions}

Cathodal tvDCS paired with rTMS is promisingly safe, feasible, and effective in potentiating RAR plus CPT outcome achievement. Furthermore, RAR alone was confirmed as effective to improve function ambulation in motor iSCI. This combined approach could be considered an effective training strategy to provide safe and efficacious neuromuscular re-education for iSCI patients once these promising data are confirmed by more extensive randomized controlled trials incorporating objective clinical and neurophysiological measures of corticospinal and spinal excitability.

Author Contributions: Conceptualization, A.N. and R.S.C.; methodology, A.N.; software, L.B.; validation, R.S.C.; formal analysis, A.N.; investigation, L.B., P.L. and T.B.; resources, M.P.O.; data curation, L.B.; writing—original draft preparation, A.N.; writing—review and editing, R.S.C.; visualization, M.P.O.; supervision, R.S.C.; project administration, R.S.C.; funding acquisition, M.P.O. All authors have read and agreed to the published version of the manuscript.

Funding: This research received no external funding. 
Institutional Review Board Statement: The study was conducted according to the guidelines of the Declaration of Helsinki and approved by the Ethics Committee of the IRCCS Centro Neurolesi Bonino Pulejo (Messina, Italy; Protocol Code 43/2016).

Informed Consent Statement: Informed consent was obtained from all subjects involved in the study.

Data Availability Statement: The data presented in this study are available upon request from the corresponding author.

Conflicts of Interest: The authors declare no conflict of interest.

\section{References}

1. The National Spinal Cord Injury Statistical Center. Spinal cord injury facts and figures at a glance. J. Spinal Cord Med. 2012, 35, 197-198. [CrossRef]

2. Graham, J.E.; Granger, C.V.; Karmarkar, A.M.; Deutsch, A.; Niewczyk, P.; DiVita, M.A.; Ottenbacher, K.J. The Uniform Data System for Medical Rehabilitation: Report of follow-up information on patients discharged from inpatient rehabilitation programs in 2002. Am. J. Phys. Med. Rehabil. 2014, 93, 231-244. [CrossRef] [PubMed]

3. Chang, F.; Zhang, Q.; Xie, H.; Yang, Y.; Sun, M.; Wu, A.; Wu, J.; Chen, G.; Shen, F.; Li, C.; et al. Effects of a rehabilitation program for individuals with chronic spinal cord injury in Shanghai, China. BMC Health Serv. Res. 2020, 20, 298. [CrossRef] [PubMed]

4. Mekki, M.; Delgado, A.D.; Fry, A.; Putrino, D.; Huang, V. Robotic Rehabilitation and Spinal Cord Injury: A Narrative Review. Neurotherapeutics 2018, 15, 604-617. [CrossRef] [PubMed]

5. AuYong, N.; Lu, D.C. Neuromodulation of the Lumbar Spinal Locomotor Circuit. Neurosurg. Clin. N. Am. 2014, 25, 15-23. [CrossRef] [PubMed]

6. Martinez, M.; Brown, A. From cortex to cord: Motor circuit plasticity after spinal cord injury. Neural Regen. Res. 2019, 14, 2054-2062. [CrossRef] [PubMed]

7. Jo, H.J.; Perez, M.A. Corticospinal-motor neuronal plasticity promotes exercise-mediated recovery in humans with spinal cord injury. Brain 2020, 143, 1368-1382. [CrossRef] [PubMed]

8. Dietz, V.; Colombo, G.; Jensen, L.; Baumgartner, L. Locomotor capacity of spinal cord in paraplegic patients. Ann. Neurol. 1995, 37, 574-582. [CrossRef]

9. Field-Fote, E.C.; Roach, K.E. Influence of a Locomotor Training Approach on Walking Speed and Distance in People with Chronic Spinal Cord Injury: A Randomized Clinical Trial. Phys. Ther. 2011, 91, 48-60. [CrossRef]

10. Calabrò, R.S.; Cassio, A.; Mazzoli, D.; Andrenelli, E.; Bizzarini, E.; Campanini, I.; Carmignano, S.M.; Cerulli, S.; Chisari, C.; Colombo, V.; et al. Italian Consensus Conference on Robotics in Neurorehabilitation (CICERONE). What does evidence tell us about the use of gait robotic devices in patients with multiple sclerosis? A comprehensive systematic review on functional outcomes and clinical recommendations. Eur. J. Phys. Rehabil. Med. 2021, 57, 841-849.

11. Swinnen, E.; Duerinck, S.; Baeyens, J.; Meeusen, R.; Kerckhofs, E. Effectiveness of robot-assisted gait training in persons with spinal cord injury: A systematic review. J. Rehabil. Med. 2010, 42, 520-526. [CrossRef] [PubMed]

12. Morawietz, C.; Moffat, F. Effects of Locomotor Training After Incomplete Spinal Cord Injury: A Systematic Review. Arch. Phys. Med. Rehabil. 2013, 94, 2297-2308. [CrossRef] [PubMed]

13. Fang, C.-Y.; Tsai, J.-L.; Li, G.-S.; Lien, A.S.-Y.; Chang, Y.-J. Effects of Robot-Assisted Gait Training in Individuals with Spinal Cord Injury: A Meta-analysis. BioMed Res. Int. 2020, 2020, 2102785. [CrossRef] [PubMed]

14. Burns, S.P.; Golding, D.G.; Rolle, W.A.; Graziani, V.; Ditunno, J.F. Recovery of ambulation in motor-incomplete tetraplegia. Arch. Phys. Med. Rehabil. 1997, 78, 1169-1172. [CrossRef]

15. van Middendorp, J.J.; Hosman, A.J.; Pouw, M.H.; Van de Meent, H.; EM-SCI Study Group. ASIA impairment scale conversion in traumatic SCI: Is it related with the ability to walk? A descriptive comparison with functional ambulation outcome measures in 273 patients. Spinal Cord 2009, 47, 555-560. [CrossRef] [PubMed]

16. Takeoka, A. Proprioception: Bottom-up directive for motor recovery after spinal cord injury. Neurosci. Res. 2020, 154, 1-8. [CrossRef]

17. Kumru, H.; Gunduz, A.; Rothwell, J.; Vidal, J. Non-invasive brain stimulation to promote motor and functional recovery following spinal cord injury. Neural Regen. Res. 2017, 12, 1933-1938. [CrossRef]

18. Leemhuis, E.; De Gennaro, L.; Pazzaglia, A.M. Disconnected Body Representation: Neuroplasticity Following Spinal Cord Injury J. Clin. Med. 2019, 8, 2144. [CrossRef]

19. Pollock, A.; Farmer, S.E.; Brady, M.C.; Langhorne, P.; Mead, G.E.; Mehrholz, J.; van Wijck, F. Interventions for improving upper limb function after stroke. Cochrane Database Syst. Rev. 2013, 2014, 1-136. [CrossRef]

20. Mazzoleni, S.; Duret, C.; Grosmaire, A.G.; Battini, E. Combining Upper Limb Robotic Rehabilitation with Other Therapeutic Approaches after Stroke: Current Status, Rationale, and Challenges. BioMed Res. Int. 2017, 2017, 8905637. [CrossRef]

21. Fleerkotte, B.M.; Koopman, B.; Buurke, J.H.; Van Asseldonk, E.H.F.; Van Der Kooij, H.; Rietman, J.S. The effect of impedancecontrolled robotic gait training on walking ability and quality in individuals with chronic incomplete spinal cord injury: An explorative study. J. Neuroeng. Rehabil. 2014, 11, 26. [CrossRef] [PubMed] 
22. Amatachaya, S.; Naewla, S.; Srisim, K.; Arrayawichanon, P.; Siritaratiwat, W. Concurrent validity of the 10-meter walk test as compared with the 6-minute walk test in patients with spinal cord injury at various levels of ability. Spinal Cord 2014, 52, 333-336. [CrossRef] [PubMed]

23. Jackson, A.B.; Carnel, C.T.; Ditunno, J.F.; Read, M.S.; Boninger, M.; Schmeler, M.R.; Williams, S.R.; Donovan, W.H. Outcome Measures for Gait and Ambulation in the Spinal Cord Injury Population. J. Spinal Cord Med. 2008, 31, 487-499. [CrossRef] [PubMed]

24. van Hedel, H.; Wirz, M.; Curt, A. Improving walking assessment in subjects with an incomplete spinal cord injury: Responsiveness. Spinal Cord 2005, 44, 352-356. [CrossRef] [PubMed]

25. Podsiadlo, D.; Richardson, S. The Timed "Up \& Go": A Test of Basic Functional Mobility for Frail Elderly Persons. J. Am. Geriatr. Soc. 1991, 39, 142-148. [CrossRef]

26. Ng, S.S.; Hui-Chan, C.W. The timed up \& go test: Its reliability and association with lower-limb impairments and loco-motor capacities in people with chronic stroke. Arch. Phys. Med. Rehabil. 2005, 86, 1641-1647. [PubMed]

27. Ditunno, J.F.; Ditunno, P.L.; Scivoletto, G.; Patrick, M.; Dijkers, M.; Barbeau, H.; Burns, A.S.; Marino, R.; Schmidt-Read, M. The Walking Index for Spinal Cord Injury (WISCI/WISCI II): Nature, metric properties, use and misuse. Spinal Cord 2013, 51, 346-355. [CrossRef]

28. Ottenbacher, K.J.; Hsu, Y.; Granger, C.V.; Fiedler, R.C. The reliability of the functional independence measure: A quantitative review. Arch. Phys. Med. Rehabil. 1996, 77, 1226-1232. [CrossRef]

29. Linacre, J.M.; Heinemann, A.W.; Wright, B.D.; Granger, C.V.; Hamilton, B.B. The structure and stability of the Functional Independence Measure. Arch. Phys. Med. Rehabil. 1994, 75, 127-132. [CrossRef]

30. Reed, M.D.; van Nostran, W. Assessing pain intensity with the visual analog scale: A plea for uniformity. J. Clin. Pharmacol. 2014, 54, 241-244. [CrossRef] [PubMed]

31. Awai, L.; Bolliger, M.; Ferguson, A.R.; Courtine, G.; Curt, A. Influence of Spinal Cord Integrity on Gait Control in Human Spinal Cord Injury. Neurorehabilit. Neural Repair 2016, 30, 562-572. [CrossRef]

32. Shin, J.C.; Kim, J.Y.; Park, H.K.; Kim, N.Y. Effect of Robotic-Assisted Gait Training in Patients with Incomplete Spinal Cord Injury Ann. Rehabil. Med. 2014, 38, 719-725. [CrossRef] [PubMed]

33. Astolfi, L.; Bakardjian, H.; Cincotti, F.; Mattia, D.; Marciani, M.G.; De Vico Fallani, F.; Colosimo, A.; Salinari, S.; Miwakeichi, F.; Yamaguchi, Y.; et al. Estimate of causality between independent cor-tical spatial patterns during movement volition in spinal cord injured patients. Brain Topogr. 2007, 19, 107-123. [CrossRef]

34. Blanc, Y.; Dimanico, U. Electrode placement in surface electromyography (sEMG) "minimal crosstalk area" (MCA). Open Rehabil. J. 2010, 3, 110-126. [CrossRef]

35. Bönstrup, M.; Krawinkel, L.; Schulz, R.; Cheng, B.; Feldheim, J.; Thomalla, G.; Cohen, L.G.; Gerloff, C. Low-Frequency Brain Oscillations Track Motor Recovery in Human Stroke. Ann. Neurol. 2019, 86, 853-865. [CrossRef]

36. Burns, A.S.; Marino, R.; Kalsi-Ryan, S.; Middleton, J.W.; Tetreault, L.A.; Dettori, J.R.; Mihalovich, K.E.; Fehlings, M. Type and Timing of Rehabilitation Following Acute and Subacute Spinal Cord Injury: A Systematic Review. Glob. Spine J. 2017, 7, 175S-194S [CrossRef] [PubMed]

37. Winchester, P.; McColl, R.; Querry, R.; Foreman, N.; Mosby, J.; Tansey, K.; Williamson, J. Changes in supraspinal activation patterns following robotic locomotor therapy in motor-incomplete spinal cord injury. Neurorehabilit. Neural Repair 2005, 19, 313-324. [CrossRef] [PubMed]

38. Sliwinski, C.; Nees, T.A.; Puttagunta, R.; Weidner, N.; Blesch, A. Sensorimotor activity partially ameliorates pain and reduces nociceptive fiber density in the chronically injured spinal cord. J. Neurotrauma 2018, 35, 2222-2238. [CrossRef]

39. Nees, T.A.; Tappe-Theodor, A.; Sliwinski, C.; Motsch, M.; Rupp, R.; Kuner, R.; Weidner, N.; Blesch, A. Early-onset treadmill training reduces mechanical allodynia and modulates calcitonin gene-related peptide fiber density in lamina III/IV in a mouse model of spinal cord contusion injury. Pain 2016, 157, 687-697. [CrossRef] [PubMed]

40. Mehrholz, J.; Kugler, J.; Pohl, M. Locomotor training for walking after spinal cord injury. Cochrane Database Syst. Rev. 2007, $33,768$. [CrossRef]

41. Athanasiou, A.; Klados, M.A.; Pandria, N.; Foroglou, N.; Kavazidi, K.R.; Polyzoidis, K.; Bamidis, P.D. A Systematic Review of Investigations into Functional Brain Connectivity Following Spinal Cord Injury. Front. Hum. Neurosci. 2017, 11, 517. [CrossRef] [PubMed]

42. Athanasiou, A.; Klados, M.A.; Styliadis, C.; Foroglou, N.; Polyzoidis, K.; Bamidis, P.D. Investigating the role of $\alpha$ and $\beta$ rhythms in functional motor networks. Neuroscience 2016, 378, 54-70. [CrossRef] [PubMed]

43. Raithatha, R.; Carrico, C.; Powell, E.S.; Westgate, P.M.; Ii, K.C.C.; Lee, K.; Dunsmore, L.; Salles, S.; Sawaki, L. Non-invasive brain stimulation and robot-assisted gait training after incomplete spinal cord injury: A randomized pilot study. NeuroRehabilitation 2016, 38, 15-25. [CrossRef] [PubMed]

44. Shapkova, E.Y.; Pismennaya, E.V.; Emelyannikov, D.V.; Ivanenko, Y. Exoskeleton Walk Training in Paralyzed Individuals Benefits from Transcutaneous Lumbar Cord Tonic Electrical Stimulation. Front. Neurosci. 2020, 14, 416. [CrossRef]

45. de Paz, R.H.; Serrano-Muñoz, D.; Pérez-Nombela, S.; Bravo-Esteban, E.; Avendaño-Coy, J.; Gómez-Soriano, J. Combining transcranial direct-current stimulation with gait training in patients with neurological disorders: A systematic review. J. NeuroEng. Rehabil. 2019, 16, 114. [CrossRef] [PubMed] 
46. Powell, E.S.; Carrico, C.; Raithatha, R.; Salyers, E.; Ward, A.; Sawaki, L. Transvertebral direct current stimulation paired with loco-motor training in chronic spinal cord injury: A case study. NeuroRehabilitation 2016, 38, 27-35. [CrossRef] [PubMed]

47. Zheng, Y.; Mao, Y.-R.; Yuan, T.-F.; Xu, D.-S.; Cheng, L.-M. Multimodal treatment for spinal cord injury: A sword of neuroregeneration upon neuromodulation. Neural Regen. Res. 2020, 15, 1437-1450. [CrossRef]

48. Brunoni, A.R.; Nitsche, M.A.; Bolognini, N.; Bikson, M.; Wagner, T.; Merabet, L.; Edwards, D.J.; Valero-Cabré, A.; Rotenberg, A.; Pascual-Leone, A.; et al. Clinical research with transcranial direct current stimulation (tDCS): Challenges and future directions. Brain Stimul. 2012, 5, 175-195. [CrossRef] [PubMed]

49. Behrman, A.L.; Bowden, M.G.; Nair, P.M. Neuro-plasticity after spinal cord injury and training: An emerging paradigm shift in rehabilitation and walking recovery. Phys. Ther. 2006, 86, 1406-1425. [CrossRef] [PubMed]

50. Dietz, V. Neuronal plasticity after a human spinal cord injury: Positive and negative effects. Exp. Neurol. 2012, 235, 110-115. [CrossRef]

51. Jurkiewicz, M.T.; Mikulis, D.J.; McIlroy, W.E.; Fehlings, M.G.; Verrier, M.C. Sensorimotor cortical plasticity during recovery following spinal cord injury: A longitudinal fMRI study. Neurorehabil. Neural Repair 2007, 21, 527-538. [CrossRef] [PubMed]

52. Lynskey, J.V.; Belanger, A.; Jung, R. Activity-dependent plasticity in spinal cord injury. J. Rehabil. Res. Dev. 2008, 45, 229-240. [CrossRef] [PubMed]

53. Edgerton, V.R.; De Leon, R.D.; Harkema, S.J.; Hodgson, J.A.; London, N.; Reinkensmeyer, D.J.; Roy, R.R.; Talmadge, R.J.; Tillakaratne, N.J.; Timoszyk, W.; et al. Retraining the injured spinal cord. J. Physiol. 2001, 533, 15-22. [CrossRef] [PubMed]

54. Fregni, F.; Pascual-Leone, A. Technology insight: Non-invasive brain stimulation in neurology-perspectives on the therapeutic potential of rTMS and tDCS. Nat. Clin. Pract. Neurol. 2007, 3, 383-393. [CrossRef] [PubMed]

55. Bocci, T.; Marceglia, S.; Vergari, M.; Cognetto, V.; Cogiamanian, F.; Sartucci, F.; Priori, A. Transcutaneous spinal direct current stimulation modulates human corticospinal system excitability. J. Neurophysiol. 2015, 114, 440-446. [CrossRef] [PubMed]

56. Bocci, T.; Vannini, B.; Torzini, A.; Mazzatenta, A.; Vergari, M.; Cogiamanian, F.; Priori, A.; Sartucci, F. Cathodal transcutaneous spinal direct current stimulation (tsDCS) improves motor unit recruitment in healthy subjects. Neurosci. Lett. 2014, 578, 75-79. [CrossRef]

57. Cogiamanian, F.; Vergari, M.; Pulecchi, F.; Marceglia, S.; Priori, A. Effect of spinal transcutaneous direct current stimulation on somatosensory evoked potentials in humans. Clin. Neurophysiol. 2008, 119, 2636-2640. [CrossRef]

58. Cogiamanian, F.; Vergari, M.; Schiaffi, E.; Marceglia, S.; Ardolino, G.; Barbieri, S.; Priori, A. Transcutaneous spinal cord direct current stimulation inhibits the lower limb nociceptive flexion reflex in human beings. Pain 2011, 152, 370-375. [CrossRef] [PubMed]

59. Hubli, M.; Dietz, V.; Schrafl-Altermatt, M.; Bolliger, M. Modulation of spinal neuronal excitability by spinal direct currents and locomotion after spinal cord injury. Clin. Neurophysiol. 2013, 124, 1187-1195. [CrossRef]

60. Truini, A.; Vergari, M.; Biasiotta, A.; La Cesa, S.; Gabriele, M.; Di Stefano, G.; Cambieri, C.; Gruccu, G.; Inghilleri, M.; Priori, A Transcutaneous spinal direct current stimulation inhibits nociceptive spinal pathway conduction and increases pain tolerance in humans. Eur. J. Pain 2011, 15, 1023-1027. [CrossRef] [PubMed]

61. Calabrò, R.S.; Cacciola, A.; Bertè, F.; Manuli, A.; Leo, A.; Bramanti, A.; Naro, A.; Milardi, D.; Bramanti, P. Robotic gait rehabilitation and substitution devices in neurological disorders: Where are we now? Neurol. Sci. 2016, 37, 503-514. [CrossRef] [PubMed]

62. Calabrò, R.S.; Naro, A.; Russo, M.; Bramanti, P.; Carioti, L.; Balletta, T.; Buda, A.; Manuli, A.; Filoni, S.; Bramanti, A. Shaping neuroplasticity by using powered exoskeletons in patients with stroke: A randomized clinical trial. J. Neuroeng. Rehabil. 2018, 15, 35. [CrossRef] [PubMed]

63. Cardoso, J.F. Source separation using higher order moments. Proc. I.C.A.S.S.P. 1989, 4, 2109-2112.

64. Chen, I.-H.; Yang, Y.-R.; Lu, C.-F.; Wang, R.-Y. Novel gait training alters functional brain connectivity during walking in chronic stroke patients: A randomized controlled pilot trial. J. Neuroeng. Rehabil. 2019, 16, 33. [CrossRef] [PubMed]

65. Cheng, P.Y.; Lai, P.Y. Comparison of Exoskeleton Robots and End-Effector Robots on Training Methods and Gait Biomechanics. In Intelligent Robotics and Applications; Lee, J., Lee, M.C., Liu, H., Ryu, J.H., Eds.; ICIRA Lecture Notes in Computer Science; Springer: Berlin/Heidelberg, Germany, 2013.

66. Rosenbaum, P.R.; Rubin, D.B. The Central Role of the Propensity Score in Observational Studies for Causal Effects. Biometrika 1983, 70, 41-55. [CrossRef] 